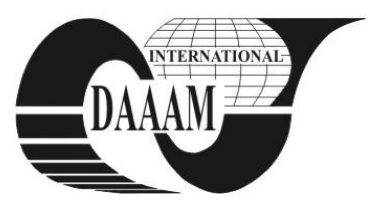

Annals of DAAAM for 2012 \& Proceedings of the 23rd International DAAAM Symposium, Volume 23, No.1, ISSN 2304-1382 ISBN 978-3-901509-91-9, CDROM version, Ed. B. Katalinic, Published by DAAAM International, Vienna, Austria, EU, 2012 Make Harmony between Technology and Nature, and Your Mind will Fly Free as a Bird Annals \& Proceedings of DAAAM International 2012

\title{
ASPECTS OF THE DYNAMICS OF THE MANUFACTURING USING ELECTRO-EROSION PROCESSES
}

\author{
DRAGOMIRESCU, C[ristian] G[eorge] \& ILIESCU, V[ictor]
}

\begin{abstract}
The paper is analyzing, from a dynamical point of view, the drilling of circular holes with massive electrodes, using spark erosion/electro-erosion technologies.

Due to the various domains of use (machine tools, metering devices, various tools manufacturing etc.) and various materials suitable for being processed using this technology, we consider the spark erosion technologies as an actual one.

The proposed model was developed and used to perform an analytical study and run a numerical simulation. Out of the numerical simulation, several conclusions emerged.

Keywords: spark erosion, electro-erosion, forced oscillation, differential equation, dynamic system
\end{abstract}

\section{INTRODUCTION}

The technologies involving moulding and casting, forging, cold forming, plastic deformation, splintering processes, sintering, agglomeration etc. are all somehow limited in terms of dimensions of the processed element and precision. That led to the development of new methods, such as spark erosion [4].

The spark erosion/electro-erosion technology is using multiple arc flashes between the processed piece and the electrode (see figure 1).

There are two metallic elements (electrodes) separated by a liquid dielectric and connected to a source of electrical energy. If the voltage and power of the source are enough, between the electrodes a discharge is generated. The discharge is a complex phenomenon, having multiple phases: flash, spark, spark-arc and arc. In order to use this phenomenon for metallic material processing, certain rules are compulsory: a) the electric energy must be introduced directly on the surface of the processed element, b) the electric energy must be in impulses, c) the discharges must keep a certain polarization and d) the conditions must be preserved by permanently adjusting the configuration of the system considering the eroded particles [7].

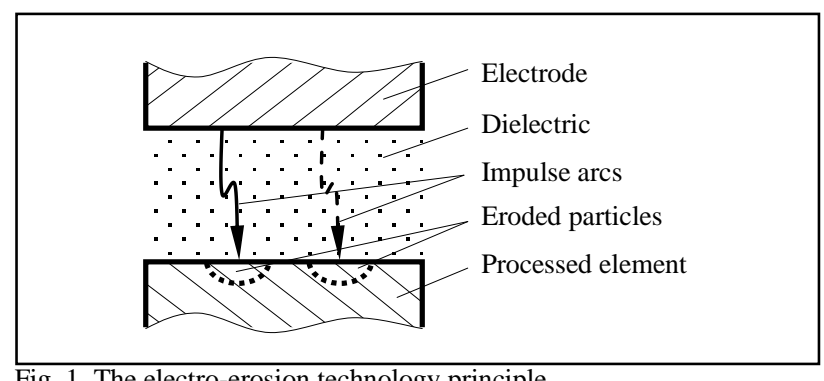

Fig. 1. The electro-erosion technology principle

According to the mode of ignition and the mode of electrical discharge, there are two basic varieties of electro-erosion technology [4]: a) electro-erosion processing with discharges ignited by puncturing the liquid dielectric and b) electro-erosion processing with permanent contact between the metallic elements with discharges ignited by disrupting the temporary electric contacts established between the two electrodes.

In the second case- the case studied in the present paper [4], we must apply pressure in order to establish the permanent contact between the two electrodes and, accordingly, a relative motion of them. Because of the disruptive discharges, a certain quantity of heat is generated in the contact areas, according to the JouleLorentz effect. The edges of the roughness of the two surfaces, when in contact, are establishing the electric contact, by the disruption of which enough heat is generated in order to melt and vaporize the edge of the processed element. The tool electrode is cooled so is not being vaporized. Due to the relative motion between the two electrodes, others and others, edges are in contact maintaining the process.

D.c. current may be used in liquid environment and a.c. current in dry environment (air) [5]. In case of d.c. current, using 20-40 V and 1000A max., a reduction of the damaged superficial layer is obtained together with a $100-150 \%$ wear increase of the tool electrode. The simplified scheme of the electro-erosion technology is presented in figure 2 [7].

The papers about electro-erosion processes are pointing out the interest for electro-erosion technologies in relation with modern materials [1], [2], aiming to the modernization of the existing technologies in order to broaden their the area of use [5], [6], [8], [9] and to the optimization of the process parameters. [1], [6], [8]. In the same time, an increase in manufacturing of the specific machines, devices and tools may be observed.

It is to be noted that only a reduced number of papers is studying the mechanical dynamics of the process.

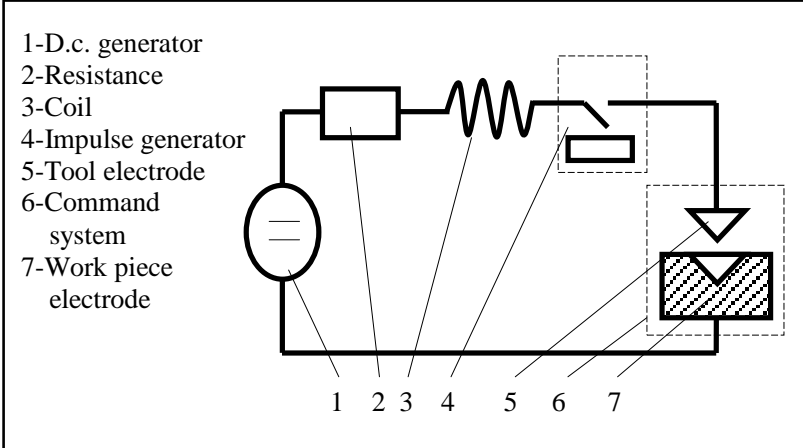

Fig. 2. The simplified scheme of the electro-erosion technology 


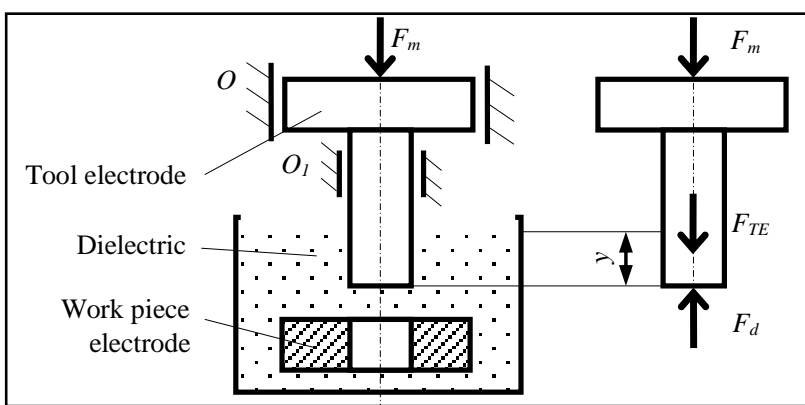

Fig. 3. The studied mechanical model

Out of all domains of use, the present paper is going to study the dynamics of the process of circular holes drilling, with massive electrodes, using electroerosion/spark erosion technology, because this operation is widely used in industry [6], [7].

\section{THE MECHANICAL STUDY MODEL}

We consider the tool electrode having the unit weight $\gamma_{T E}$, the length $l$ and the transversal area $A$. The tool electrode is moving downwards in a liquid dielectric having the unit weight $\gamma_{d}$ (see figure 3). Accordingly, the mass of the tool electrode is: $M=\gamma_{T E} A l, g$ being the acceleration of gravity.

If we do not consider the drag of the dielectric and we assume that the tool electrode is not entirely immersed, we obtain the following forces acting upon the electrode tool: $F_{m}$ - the force of the machine tool, $F_{T E}=\gamma_{T E} A l g-$ the weight of the tool electrode, $F_{d}=\gamma_{d} A y g$ - the force applied by the dielectric, according to Archimedes principle. Accordingly, the motion equation on the motion direction of the tool electrode (vertical) is [10]:

$$
M \ddot{y}=F_{m}+F_{T E}-F_{d} \Leftrightarrow \ddot{y}+\frac{\gamma_{d} g}{\gamma_{T E} l} y=g+\frac{F_{m}}{\gamma_{T E} A l} .
$$

Equation (1) is a differential, linear non-homogenous equation.

\subsection{A constant force of the machine tool}

Assuming that $F_{m}$ is constant, (1) is having constant coefficients and the general solution [2], is given by the sum of the solutions of both homogenous and nonhomogenous equation: $y=y_{h}+y_{n}$. Because the roots of the attached characteristic equation $\lambda^{2}+\frac{\gamma_{d} g}{\gamma_{T E} l}=0$ are imaginary: $\lambda_{1,2}= \pm i \sqrt{\frac{\gamma_{d} g}{\gamma_{T E} l}}$ and the particular solution is: $y_{p}=\frac{\gamma_{T E} l}{\gamma_{d}}+\frac{F_{m}}{\gamma_{d} A g}$, the general solution of (1) is:

$$
y=C_{1} \cos \left(t \sqrt{\frac{\gamma_{d} g}{\gamma_{T E}}}\right)+C_{2} \sin \left(t \sqrt{\frac{\gamma_{d} g}{\gamma_{T E} l}}\right)+\frac{\gamma_{T E} l}{\gamma_{d}}+\frac{F_{m}}{\gamma_{d} A g} .
$$

Considering the initial conditions of the dynamic system: $t=0 \Rightarrow y=0, \dot{y}=v_{0}$, the constants are: $C_{1}=-\frac{\gamma_{T E} l}{\gamma_{d}}+\frac{F_{m}}{\gamma_{d} A g}$ and $C_{2}=-v_{0} \sqrt{\frac{\gamma_{T E}}{\gamma_{d} g}}$.

Finally, we obtain the solution of (1) as follows:

$$
y=\left(\frac{\gamma_{T E} l}{\gamma_{d}}+\frac{F_{m}}{\gamma_{d} A g}\right)\left[1-\cos \left(t \sqrt{\frac{\gamma_{d} g}{\gamma_{T E}}}\right)\right]+
$$

$$
+v_{0} \sqrt{\frac{\gamma_{T E} l}{\gamma_{d} g}} \sin \left(t \sqrt{\frac{\gamma_{d} g}{\gamma_{T E} l}}\right) .
$$

Equation (3) is representing the motion of the tool electrode in any moment of the process, if the following condition is fulfilled: $y_{\max } \leq l$ or $\gamma_{T E} \leq \frac{\gamma_{d}}{2}$.

One may now calculate the speed and acceleration of the tool electrode:

$$
\left.\begin{array}{c}
\dot{y}=\left(\frac{\gamma_{T E} l}{\gamma_{d}}+\frac{F_{m}}{\gamma_{d} A g}\right) \sqrt{\frac{\gamma_{d} g}{\gamma_{T E} l}} \sin \left(t \sqrt{\frac{\gamma_{d} g}{\gamma_{T E} l}}\right)+v_{0} \cos \left(t \sqrt{\frac{\gamma_{d} g}{\gamma_{T E} l}}\right) \\
\ddot{y}=\left(\frac{\gamma_{T E} l}{\gamma_{d}}+\frac{F_{m}}{\gamma_{d} A g}\right) \frac{\gamma_{d} g}{\gamma_{T E} l} \cos \left(t \sqrt{\frac{\gamma_{d} g}{\gamma_{T E} l}}\right)-v_{0} \sqrt{\frac{\gamma_{d} g}{\gamma_{T E} l}} \sin \left(t \sqrt{\frac{\gamma_{d} g}{\gamma_{T E} l}}\right)
\end{array}\right\} \text { (4) }
$$

\subsection{A variable force of the machine tool}

Assuming that $F_{m}$ is a time function, $F_{m}=F_{0} \sin (\Omega t)$, (1) may be written as follows:

$$
\ddot{y}+\omega^{2} y=g+F_{0}^{\prime} \sin (\Omega t),
$$

where $\omega^{2}=\frac{\gamma_{d} g}{\gamma_{T E} l}$ and $F_{0}^{\prime}=\frac{F_{0} g}{\gamma_{T E} A l}$.

Assuming the variable change: $y=u+\frac{g}{\omega^{2}}$, becomes:

$$
\ddot{u}+\omega^{2} u=F_{0}^{\prime} \sin (\Omega t) .
$$

The general solution of (6) is [2]:

$$
u=A^{\prime} \sin (\omega t+\varphi)+\frac{F_{0}^{\prime}}{\omega^{2}-\Omega^{2}} \sin (\Omega t)
$$

Out of (7) one may observe that the forced oscillation is determined by the particular solution $u=\frac{F_{0}^{\prime}}{\omega^{2}-\Omega^{2}} \sin (\Omega t)$.

Considering the same initial condition of the dynamic system as previously, we may obtain the values of the constants $A^{\prime}$ and $\operatorname{tg} \varphi$ :

$$
A^{\prime}=\sqrt{\left(\frac{g}{\omega^{2}}\right)^{2}+\left[\frac{v_{0}}{\omega}-\frac{\Omega F_{0}^{\prime}}{\omega\left(\omega^{2}-\Omega^{2}\right)}\right]^{2}}, \tan \varphi=-\frac{g}{\omega\left(v_{0}-\frac{\Omega F_{0}^{\prime}}{\omega^{2}-\Omega^{2}}\right)} .
$$

Using (7) and (8), the speed and acceleration of the tool electrode may be obtained:

$$
\left.\begin{array}{l}
\dot{u}=A^{\prime} \cos (\omega t+\varphi)+\frac{\Omega F_{0}^{\prime}}{\omega^{2}-\Omega^{2}} \cos (\Omega t) \\
\ddot{u}=A^{\prime 2} \sin (\omega t+\varphi)-\frac{\Omega^{2} F_{0}^{\prime}}{\omega^{2}-\Omega^{2}} \sin (\Omega t)
\end{array}\right\} .
$$

\subsection{Considering the electric circuit}

In both above cases, we did not consider the electric circuit. If we do, as would be normal, we will have to study a dynamic system with two degree of freedom [3].

In order to do so, we consider $R$ - the value of the resistance of the electric resistor, $L-$ the value of the inductance of the coil, $U$ - the voltage of the electric generator (see figure 2) and $q$ - the quantity of electricity at a given moment $t$. It is to be mentioned that the inductance of the coil is varying with the displacement $y$ of the tool electrode (see figure 3 ). 
In these conditions, the differential equations systems are calculated [10] for both constant and variable $F_{m}$.

a) The case of a constant force of the machine tool:

$$
\left\{\begin{array}{c}
\ddot{y}+\frac{\gamma_{d} g}{\gamma_{T E} l} y-\frac{1}{2} \frac{\partial L}{\partial y} \dot{q}=g+\frac{F_{m}}{\gamma_{T E} A l} \\
L \ddot{q}+R \dot{q}+\frac{\partial L}{\partial y} \dot{q} \dot{y}=U
\end{array}\right.
$$

b) The case of a variable force of the machine tool:

$$
\left\{\begin{array}{c}
\ddot{y}+\frac{\gamma_{d} g}{\gamma_{T E} l} y-\frac{1}{2} \frac{\partial L}{\partial y} \dot{q}^{2}=g+\frac{F_{0}}{\gamma_{T E} A l} \sin (\Omega t) \\
L \ddot{q}+R \dot{q}+\frac{\partial L}{\partial y} \dot{q} \dot{y}=U
\end{array} .\right.
$$

We assume that $\mathrm{L}=\mathrm{L}_{0}+\varepsilon, \dot{\mathrm{q}}=\mathrm{i}_{0}+\mathrm{i}, \mathrm{Ri}_{0}=\mathrm{U}$ and we consider the case of small amplitude oscillations when following approximation may be used:

$$
\left.\begin{array}{c}
\left(i_{0}+i\right)^{2}=i_{0}^{2}+2 i_{0} i+i^{2} \approx i_{0}^{2}+2 i_{0} i \\
\varepsilon y \frac{d i}{d t}+\varepsilon \frac{d y}{d t} i=\varepsilon \frac{d(y i)}{d t} \approx 0
\end{array}\right\} .
$$

In (12) $\varepsilon$ is a constant, $i_{0}=\frac{U}{R}$ is the static current, $i$ is the variation of current from the value $i_{0}$. Note that $\frac{d q}{d t}=i_{0}+i$.

According to these hypotheses, (10) and (11) become (13) and respectively (14):

$$
\begin{gathered}
\left\{\begin{array}{c}
\ddot{y}+\frac{\gamma_{d} g}{\gamma_{T E} l} y-\varepsilon i_{0} i=\frac{\varepsilon i_{0}^{2}}{2}+g+\frac{F_{m}}{\gamma_{T E} A l}, \\
L_{0} \frac{d i}{d t}+R i+\varepsilon i_{0} \dot{y}=0
\end{array}\right. \\
\left\{\begin{array}{c}
\ddot{y}+\frac{\gamma_{d} g}{\gamma_{T E} l} y-\varepsilon i_{0} i=\frac{\varepsilon i_{0}^{2}}{2}+g+\frac{F_{0}}{\gamma_{T E} A l} \sin (\Omega t) \\
L_{0} \frac{d i}{d t}+R i+\varepsilon i_{0} \dot{y}=0
\end{array} .\right.
\end{gathered}
$$

Considering only the particular solutions of (15):

$$
\left\{\begin{array}{c}
y=C_{1}^{b}+C_{2}^{b} \sin (\Omega t-\varphi) \\
i=C_{3}^{b}+C_{4}^{b} \sin (\Omega t-\theta)
\end{array},\right.
$$

where $C_{1}^{b}, C_{2}^{b}, C_{3}^{b}, C_{4}^{b}, \varphi, \theta$ are integration constants, one may calculate:

$$
\begin{gathered}
C_{1}^{b}=\frac{\gamma_{T E} l}{2 \gamma_{d} g}\left(\varepsilon i_{0}^{2}+2 g\right) \\
C_{2}^{b}=F_{0} \sqrt{\frac{R^{2}+\Omega^{2} L_{0}^{2}}{\left(\frac{\gamma_{d} g}{\gamma_{T E} l}-\Omega^{2}\right)^{2}\left(R^{2}+\Omega^{2} L_{0}^{2}\right)+2\left(\frac{\gamma_{d} g}{\gamma_{T E} l}-\Omega^{2}\right) \varepsilon^{2} i_{0}^{2} \Omega^{2} L_{0}+\varepsilon^{4} i_{0}^{4} \Omega^{2}}} \\
C_{3}^{b}=0, C_{4}^{b}=C_{2}^{b} \frac{\varepsilon i_{0} \Omega}{\sqrt{R^{2}+\Omega^{2} L_{0}^{2}}}
\end{gathered} .
$$

\section{THE ANALYSIS OF THE EXPERIMENTAL DATAS}

The numerical simulation with specific software was based on existing values [1], [8], given in Table 1:

\begin{tabular}{|c|c|c|c|c|c|c|c|}
\hline$\gamma_{\boldsymbol{d}}$ & $\begin{array}{c}950 \\
\mathrm{~kg} / \mathrm{m}^{3}\end{array}$ & $\boldsymbol{l}$ & $60 \mathrm{~mm}$ & $\boldsymbol{v}_{\boldsymbol{\theta}}$ & $0.1 \mathrm{~m} / \mathrm{s}$ & $\boldsymbol{\varepsilon}$ & $10 \mathrm{~mm}$ \\
\hline $\boldsymbol{A}$ & $\begin{array}{c}314.16 \\
\mathrm{~mm}^{2}\end{array}$ & $\boldsymbol{F}_{\boldsymbol{m}}$ & $0.01 \mathrm{~N}$ & $\boldsymbol{i}_{\boldsymbol{\theta}}$ & $1.5 \mathrm{~A}$ & $\boldsymbol{R}$ & $10 \mathrm{Ohm}$ \\
\hline$\gamma_{T E}$ & $\begin{array}{c}2.79 \\
\mathrm{~kg} / \mathrm{ml}\end{array}$ & $\boldsymbol{F}_{\boldsymbol{0}}$ & $0.01 \mathrm{~N}$ & $\boldsymbol{\Omega}$ & $0.1 \mathrm{1} / \mathrm{s}$ & $\boldsymbol{L}_{\boldsymbol{\theta}}$ & $4.5 \mu \mathrm{H}$ \\
\hline
\end{tabular}

Tab. 1. Values used in the numerical simulation

\begin{tabular}{|l|c|c|}
\hline \multicolumn{1}{|c|}{ Time variation } & Fig. & Obs. \\
\hline$y=0.561[1-\cos (4.18 t)]+0.0239 \sin (4.18 t)$ & & \\
$v=\dot{y}=2.345 \sin (4.18 t)+0.1 \cos (4.18 t)$ & 4 & (I) \\
$a=\ddot{y}=9.812 \cos (4.18 t)-0.418 \sin (4.18 t)$ & & \\
\hline$u=0.41 \sin (4.18 t-1.51)+2.58 \cdot 10^{-3} \sin (0.1 t)$ & & \\
$u p=\dot{u}=1.972 \cos (4.18 t-1.51)+2.28 \cdot 10^{-4} \cos (0.1 t)$ & 5 and 6 & (II) \\
$u s=\ddot{u}=-9.486 \sin (4.18 t-1.51)-2.58 \cdot 10^{-5} \sin (0.1 t)$ & & \\
\hline$C_{1}^{b}=1.204 ; C_{2}^{b}=5.721 \cdot 10^{-4} ; C_{3}^{b}=0 ; C_{4}^{b}=4.29 \cdot 10^{-8}$ & & \\
$y=1.204+5.721 \sin (0.1 t-\varphi)$ & 7 and 8 & (III) \\
$i=4.29 \cdot 10^{-8} \sin (0.1 t-\varphi)$ & & \\
\hline
\end{tabular}

Tab. 2. Equations used in the numerical simulation

Using the values in Tab. 1, we may calculate the parameters of the equations as shown in Tab. 2.

(I) For the system having one degree of freedom, with a constant force $F_{m}$, one may see a variation of $y$ and $\dot{y}$ according to the mechanical vibrations theory, as well as an increasing of $\ddot{y}$. The aspect of Fig. 4 is consistent with the theory.

(II) For the system having one degree of freedom, with a variable harmonic force $F_{m}$, one may see a variation of $u$ and $\dot{u}$ according to the mechanical vibrations theory, as well as an increasing of $\ddot{u}$. The aspect of Fig. 5a and 5b is consistent with the theory for the amplification function and frequencies ratio $\eta$.

(III) For the system having two degree of freedom, with a variable harmonic force $F_{m}$, one may see major changes for the evolution in time of $y$ due to the influence of the considered parameter $i$. We may evaluate the effect of the electromagnetic field upon the dynamic of the mechanical system. We may also highlight the characteristics of such a system.

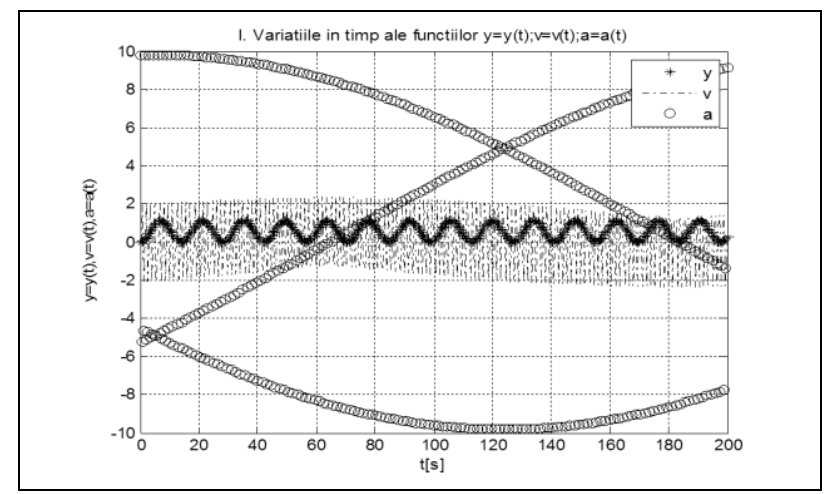

Fig. 4. Time variation of $y, v$ and $a$

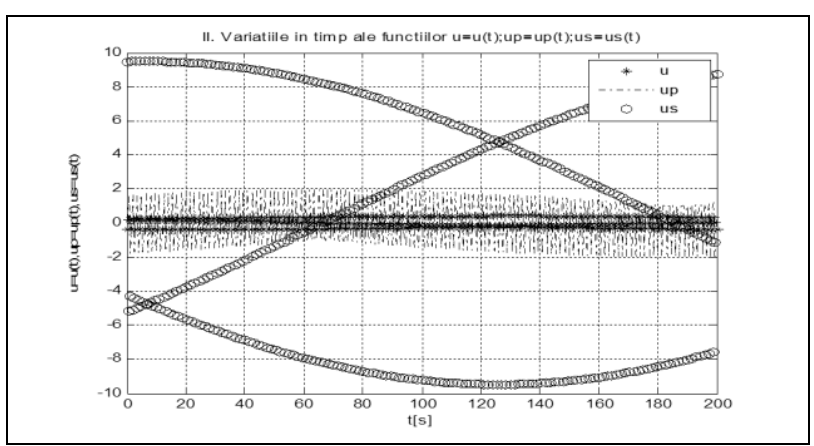

Fig. 5. Time variation of $u, u p$ and $u s$ 

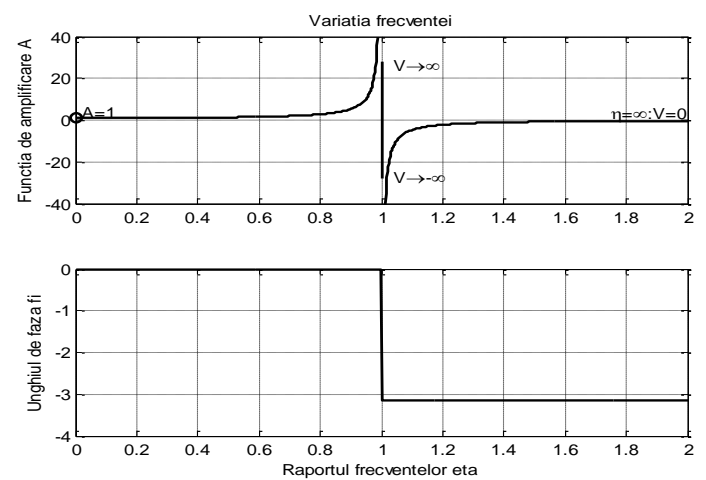

Fig. 6. Variation of the amplification function $A$ and of the phase $\varphi$

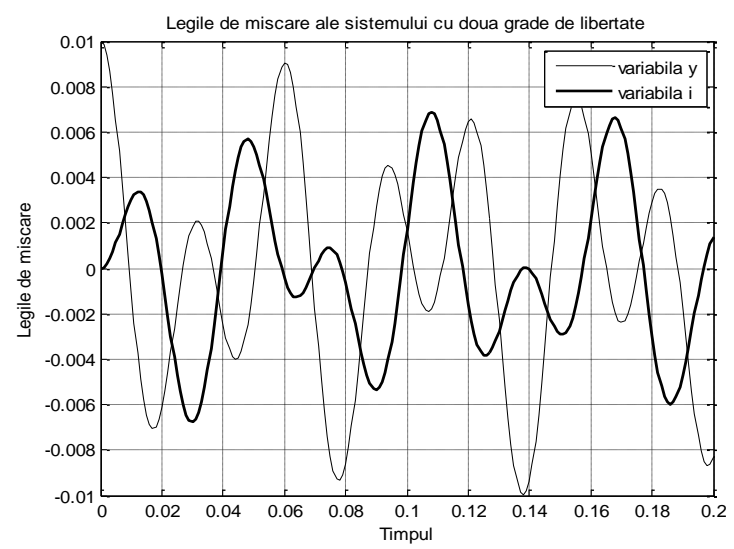

Fig. 7. Time variation of $y$ and $i$
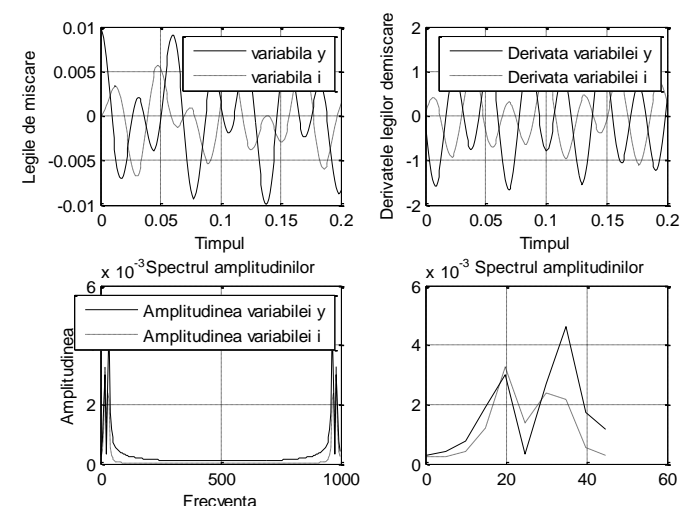

Fig. 8. Time variation of $y$ and $i$, "speed" variation for $y$ and $i$, amplitudes variation with frequencies and shape of the amplitudes

\section{CONCLUSIONS}

The paper studied the mechanical vibrations occurring during the spark erosion/electro-erosion manufacturing process.

The mechanical model proposed is considering the dynamic system for circular holes drilling process, using compact tool-electrodes. Both constant and variable forces of the machine tool were considered and also the influence of the electric circuit, in order to obtain a non linear dynamic model.

For certain conditions and hypotheses, the model allows the highlighting of the motion parameters.
Using values accepted by the specialists for the parameters of the adopted mechanical model, we developed a numerical simulation in order to notice the evolution of the most important variables.

The numerical results allow us to point out the specific elements of a mechanical vibration and implicitly some conclusions.

If the models with one degree of freedom (having a constant or variable force) are leading to similar results and all consistent with specialty papers and books, the model with two degree of freedom is allowing the study of the effect of the electromagnetic field upon the dynamic of the mechanical system, by comparing these results with the results obtained for the systems having one degree of freedom.

We must also point out that the study was developed because the scientific literature is only studying the electrical and chemical processes, even if such technologies are widely used nowadays. That is the reason we considered the study of the mechanical dynamics because vibrations may occur during the process due to the specific phenomenon, with noticeable impact at least the in case of thin tool-electrodes.

The development of the present study may lead to the optimisation of the design of the spark erosion/electroerosion tools and process parameters, significant results for an increased quality of the surfaces, increased dimensional precision, reduced consumption of energy and tool-electrodes. Furthermore, the basic idea of this study may be also used for the study of mechanical dynamics of other technologies.

\section{REFERENCES}

[1] Bolundut, I. L. (2012). Materiale si tehnologii neconvenţionale, Editura Tenhica-Info, ISBN 978-9975-63-334-5, Chişinău

[2] Deciu, E. \& Dragomirescu C. (2001). Maschinendynamic, Editura PRINTECH, ISBN 973-652-438-8, Bucureşti

[3] Dragomirescu, C. \& Iliescu, V. (2005), Some aspects of the dynamic stability of an industrial machine, Proceedings, $1^{s t}$ International Conference - Computational Mechanics and Virtual Engineering, Universitatea Transilvania din Braşov, 20-22 octombrie 2005, pag. 231-236, ISBN 973-635-593-4, Braşov

[4] Gavrilaş, I. \& Marinescu, N. I. (1991). Prelucrări neconvenţionale în construcţia de maşini (vol. I), Editura Tehnică, ISBN 973-31-0251-2, București

[5] Herman, R. I. E. et al. (2004). Tratat de tehnologi neconventionale, Vol. V-Prelucrarea prin eroziune complexă electrică-electrochimică, Editura ArtPress, ISBN 973-7836-02-2, Timişoara

[6] Marinescu, N. I.; Gavrilaş, I.; Vişan, A. \& Marinescu, R. D. (1993). Prelucrări neconvenţionale în construcţia de mașini (vol. II), Editura Tehnică, ISBN 973-31-0225-3, București

[7] Mihăilă, I. (2003). Tehnologii neconvenționale (ediția a II-a), Editura Universităţii din Oradea, ISBN 973-613-400-8, Oradea

[8] Nanu, A. (2003). Tehnologii neconvenţionale (vol. I), Editura Augusta, ISBN 973-695-071-9, Timişoara

[9] Surugiu, I. (2008). Tehnologii moderne. Prelucrarea prin electroeroziune (vol. I), Editura Electra, ISBN 978-606-507-0028, Bucureşti

[10] Voinea, R.; Deciu, E. \& Dragomirescu C. (2009), Technische Mechanik, Editura ALMA, ISBN 978-973-1792-76-7, Craiova 